\title{
空気中の揮発性有機化合物分析における熱脱着法の吸着剤 TenaxTA/Carboxen1000 の特性
}

\author{
世古 民雄 ${ }^{\circledR 1}$, 臼倉 浩一 ${ }^{2}$, 恩田 宣彦 ${ }^{2}$
}

\begin{abstract}
Characterization of a TenaxTA/Carboxen 1000 multibed tube for the thermal desorption analysis of VOCs in air
\end{abstract}

\author{
Tamio SEKo $^{1}$, Koichi UsukurA ${ }^{2}$ and Nobuhiko ONDA ${ }^{2}$ \\ ${ }^{1}$ PerkinElmer Japan Co. Ltd., 5 - 3 Toyotsu-cho, Suita-shi, Osaka 564- 0051 \\ ${ }^{2}$ PerkinElmer Japan Co. Ltd., 2 - 8-4, Kitasaiwai, Nishi-ku, Yokohama-shi, Kanagawa 220 - 0004
}

(Received 22 July 2003, Accepted 28 September 2003)

\begin{abstract}
A sorbent for the thermal desorption-GC/MS to analyze volatile organic compounds (VOC) and phthalic acid esters(PAE) in air was selected and characterized. The combination of commercial sorbents of TenaxTA and Carboxen 1000 packed in sequence into a desorption tube was applied to compounds with a wide boiling point, such as ethanol, through diethyl hexyl phthalate (DEHP). The analytical results were confirmed for the linearity of the calibration over a range of $10 \sim 500 \mathrm{ng}$ with a correlation coefficient of $0.999 \sim 1.000$, and also for a repeatability of $1.5 \sim 2.0 \%$ to VOC and $2.2 \sim 6.2 \%$ to PAE. The detection limit was found to be $0.07 \sim 2.67$ ng for 3 liters, or a detection limit of $0.02 \mu \mathrm{g} / \mathrm{m}^{3}$ for toluene. With the prepared tube, of sampled air a simultaneous analysis of VOC and PAE in indoor air and in the emitted gas from the building materials was performed.
\end{abstract}

Keywords : VOC; phthalic acid ester; thermal desorption-GC/MS; TenaxTA/Carboxen1000; indoor air.

\section{1 緒言}

「シックハウス問題」などから住宅，オフィスの生活空 間の空気質の法制化がされている ${ }^{1)}$. 室内空気污染物質と して，有機化合物では建材などに由来する揮発性有機化合 物（VOC），環境ホルモンとして注目されている難揮発性 化合物のフタル酸エステル（PAE）などがあるＶOOCに は沸点範囲の広い成分が存在しているとともに, 有害性の 高い成分あるいは化学的に活性な成分が含まれている。こ れら VOC 及びPAE の分析には固体捕集一熱脱着法が有効

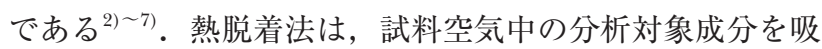
着棛の充填されたチューブに直接捕集した後オンストリー

\footnotetext{
${ }^{1}$ 株式会社パーキンエルマージャパン大阪支社応用研究部：5640051 大阪府吹田市豊津町 5-3

2 株式会社パーキンエルマージャパン応用研究部: 220-0004 神 奈川県横浜市西区北幸 2-8-4
}

ムで熱脱着-ガスクロマトグラフ/質量分析法 (GC/MS) で，対象成分に対する吸着剂の選択が重要である。従来か ら使用されている TenaxTA 吸着剂は, 破過容量が小さく 低沸点成分の採取量に限界がある ${ }^{4) 5)}$. またカーボン系吸 着剂では, ノナナールの検量線の直線性, テトラデカンの キャリーオーバー，あるいはPAEの回収率が低いなど精 度を上げる必要がある。本研究では, TenaxtA と Carboxen1000の 2 層の吸着剂を用いることによりVOC 及びPAEの分析精度を向上させ，その一斉分析法を確立 した。また，本法を室内空気分析及び空気污染の発生源と なる建材からの放散ガス分析に適応し，その有効性を明ら かにした。

$$
2 \text { 実験 }
$$

\section{$2 \cdot 1$ 試 薬}

トルエン，エチルベンゼン， キシレン，スチレン，ノナ 
Table 1 Thermal desorption-GC/MS parameters

\begin{tabular}{ll} 
Thermal desorption & \\
Desorption temp. & $300^{\circ} \mathrm{C}$ \\
Desorption flow & $30 \mathrm{ml} / \mathrm{min}$ \\
Desorption time & $10 \mathrm{~min}$ \\
Cold trap inlet split flow & $30 \mathrm{ml} / \mathrm{min}$ \\
Cold trap temp. & $5^{\circ} \mathrm{C}$ \\
Cold trap desorp. temp. & $300^{\circ} \mathrm{C}$ \\
Cold trap desorp. time & $35 \mathrm{~min}$ \\
Cold trap outlet split flow & $10 \mathrm{ml} / \mathrm{min}$ \\
GC/MS & \\
Column & PE Elite- $10.25 \mathrm{~mm} \times 60 \mathrm{~m}$, \\
& df: $0.25 \mu \mathrm{m}$ \\
Oven & $50^{\circ} \mathrm{C}(8 \mathrm{~min}) \sim\left(10^{\circ} \mathrm{C} / \mathrm{min}\right) \sim$ \\
& $120^{\circ} \mathrm{C}$ \\
& $\left(20^{\circ} \mathrm{C} / \mathrm{min}\right) \sim 280^{\circ} \mathrm{C}(18 \mathrm{~min})$ \\
Carrier gas & helium, $17 \mathrm{psi}$ \\
MS mode & SIFI $(\mathrm{SIM}-\mathrm{Scan})$ \\
Mass range & $33 \sim 400 \mathrm{~m} / z$ \\
\hline
\end{tabular}

ナール, $p$-ジクロロベンゼン, テトラデカン, トルエン $d 8$ (内標準物質) 及びVOC52 成分の混合標準物質は， シ グマアルドリッチ製を用いた.フタル酸ジブチル（DBP） 及びフタル酸ジエチルヘキシル（DEHP）を含むPAE4 成 分は東京化成製を用いた。各成分をメタノールに溶解し $1000 \mathrm{ng} / \mathrm{ml}$ の標準原液を調製した。ガスボンベ入り内標 準物質トルエン- $d 8$ （濃度 $25.4 \mathrm{ppmv}$ 窒素バランス）及び 標準試料調製用高純度空気は高千穂化学工業製を用いた。 吸着剂 TenaxTA は Enka Research Institute 製，Air Toxics は PerkinElmer 製，Carboxen1000 は SUPELCO 製を用い た。捕集チューブ（内径 $4 \mathrm{~mm}$ ，長さ $89 \mathrm{~mm}$ のガラス管） に TenaxTA $(60 / 80 \mathrm{mesh}) 100 \mathrm{mg}$ と Carboxen 1000 （45/60 mesh） $70 \mathrm{mg}$ を 2 層に充填した.

\section{$2 \cdot 2$ 装置及び測定条件}

熱脱着装置及び質量分析計には，パーキンエルマー製の サーマルデソーバーTurboMatrix ATD（内標準ガス添加 アクセサリー付き）及び Clarus 500 GC/MS を使用した。 TurboMatrix ATD の充填トラップには TenaxTA を用い, 捕集温度制御は装置内蔵の電子冷却（ペルチェ素子）を利 用した。未知試料には，濃度範囲の広い多種多様の成分が 含まれると予想されることから，Clarus $500 \mathrm{GC} / \mathrm{MS}$ の SIFI 機能によるSIM-Full Scan 同時測定を行った。分析条 件を Table 1 に示す。定流量ポンプにはAMETEK 製の ALPHA-2 を用いた。

\section{$2 \cdot 3$ 試料調製}

検量線作成用標準試料は，VOC9 成分及び PAE2 成分を 含む標準原液をメタノールで希釈して $1 ， 2 ， 5 ， 10 ， 50$, 100 及び $500 \mu \mathrm{g} / \mathrm{ml}$ の標準溶液を調製した。また，トルエ ン- $d 8$ をメタノールに溶解し， $100 \mu \mathrm{g} / \mathrm{ml}$ の内標準溶液を
調製した．標準溶液及び内標準溶液の各 $1 \mu \mathrm{l}$ をマクロ シリンジで正確に採取し，清浄な空気を一定流量（100 $\mathrm{ml} / \mathrm{min}$ ) で流しながら，捕集チューブの入口側のガラス ウール部にスパイクした。このとき清浄空気を 30 分間通 気することにより成分を気化して捕集剤に吸着させた。再 現性試験は $100 \mu \mathrm{g} / \mathrm{ml}$ の標準溶液を用い上記と同様の方 法で添加した。なお，内標準は，ボンベ入りトルエン- $d 8$ を自動添加した。実分析における室内空気の採取は，100 $\mathrm{ml} / \mathrm{min}$ の流量にコントロールされた定流量ポンプを用い て，捕集チューブの TenaxTA 側から 30 分間捕集した。 建材からの拡散ガスの採取は，20リットルの JIS 小型チ ヤンバーの出口から $100 \mathrm{ml} / \mathrm{min}$ の流量で 30 分間捕集し た。採取したそれぞれの試料チューブに上記と同様の方法 で内標準を添加した。

\section{3 結果と考察}

\section{$3 \cdot 1 \quad$ 標準試料のクロマトグラム}

VOC52 成分及び PAE4 成分（各成分 $20 \mathrm{ng}$ ）を含む混合 試料を $2 \cdot 3$ 試料調製に記した方法で捕集チューブに添加 したときの総イオンクロマトグラム（TIC）を Fig. 1 に示 す。エタノールなどの低沸点成分から高沸点成分のフタル 酸ジエチルヘキシル（DEHP）まで一つの条件で GC 分析 が可能であった。

\section{$3 \cdot 2$ 破過容量}

TenaxTA/Carboxen1000，TenaxTA 及び AirToxics（炭 素ベースの吸着剤を 2 層に充填したもの）の各捕集チュ ーブについて，GC 法 ${ }^{5) 6)} に よ り$ 求めた各種成分の破過容 量を Table 2 に示す. 破過容量が同族の化合物では炭素数 の順であることから，TenaxTA/Carboxen1000 及び AirToxics では，対象とした VOC9 成分及び PAE2 成分を 含め，エ夕ノールなどの低沸点 VOC から DEHP などの高 沸点物までの広い沸点範囲の成分に適応できることが分か る. 一方，1〜31 の試料採取量を必要とする室内空気污 染分析では，TenaxTAはエ夕ノール，ジクロロメタン， アセトンなどの低沸点成分では破過のために適応できない ことが分かる。

\section{$3 \cdot 3$ キャリーオーバー}

TenaxTA/Carboxen1000 吸着剤におけるVOC9 成分及 びPAE2 成分を分析した後のキャリーオーバー（500 ng 分析後の同チューブの空試験）の様子を Fig. 2 に示す. また，各捕集チューブにおけるテトラデカンのキャリーオ ーバーを Table 3 に示す。カーボン系吸着剤である AirToxics ではキャリーオーバーが 20\% であるのに対して TenaxTA/Carboxen1000 では 0.17\% に改善された。 


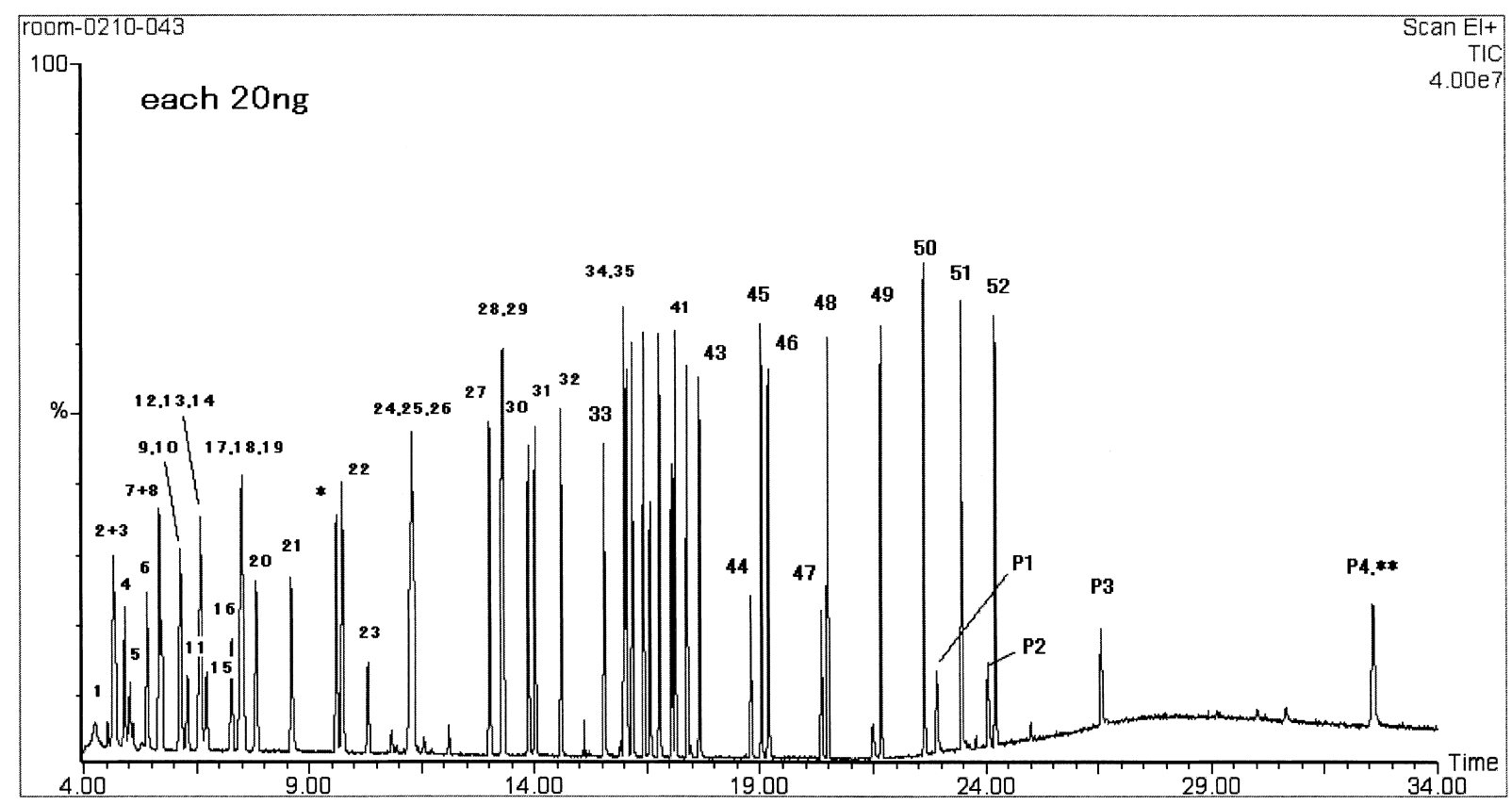

Fig. 1 TIC (Total Ion Chromatogram) of GC/MS analysis of the standard components

1. Ethanol, 2. Acetone, 3. $i$-Propanol, 4. Dichloromethane, 5. $n$-Propanol, 6. MEK, 7. Ethylacetate, 8. $n$-Hexane, 9. Chloroform, 10. 2,4-Dimethylpentane, 11. 1,2-Dichloroethane, 12. 1,1,1-Trichloroethane, 13. 1-Butanol, 14. Benzene, 15. Carbontetrachloride, 16. 1,2-Dichloropropane, 17. 2,2,4-Trimethylpentane, 18. Trichloroethylene, 19. Bromodichloromethane, 20. $n$-Heptane, 21. MIBK, 22. Toluene, 23. Dibromochloromethane, 24. $n$-Butylacetate, 25. $n$-Octane, 26. Tetrachloroechilene, 27. Ethylbenzene, 28,29. $p+m$-Xylene, 30. Styrene, 31. $o$-Xylene, 32. $n$ Nonane, 33. $a$-Pinene, 34,35. $m$, $p$-Ethyltoluene, 36. 1,3,5-TMB, 37. $o$-Ethyltoluene, 38. $\beta$-Pinene, 39. 1,2,4-TMB, 40. $n$-Decane, 41. $p$-Dichlorobenzene, 42. 1,2,3-TMB, 43. D-Limonene, 44. Nonylaldehyde, 45. n-Undecane, 46. Durene, 47. Decylaldehyde, 48. n-Dodecane, 49. Tridecane, 50. Tetradecane, 51. Pentadecane, 52. Hexadecane, P1.DMP, P2.DEP, P3.DBP, P4.DEHP, *1.Toluene- $d 8$, *2.DEHP-d4. The compounds underlined were used for the evaluation of sorbent.

Table 2 Breakthrough volume of selected compounds $^{\text {a) }}$

\begin{tabular}{lcrc}
\hline & TenaxTA $^{\mathrm{b})}$ & $\begin{array}{r}\text { TenaxTA/ } \\
\mathrm{C} 1000^{\mathrm{c})}\end{array}$ & Air Toxics $^{\mathrm{d})}$ \\
\hline Ethanol & 0.18 & 19 & 30 \\
Dichloromethane & 0.3 & 95 & 40 \\
Acetone & 0.54 & 220 & 20 \\
Methylacetate & 6.4 & 450 & 40 \\
Hexane & 3.2 & 500000 & - \\
Benzene & 6.2 & 400000 & 50 \\
\hline
\end{tabular}

a) unit in L; b) $200 \mathrm{mg}$; c) C1000 : Carboxen1000 ; d) Carbon base, 2 phases prepacked

\section{$3 \cdot 4$ 試料保存性}

VOC9 成分及び PAE2 成分の各 $100 \mathrm{ng}$ を含む標準試料 を捕集したチューブをテフロン製フェラルと真ちゅうナッ ト（スウエジロックタイプ）で密閉した後，デシケーター 内で保管して保存性試験を行った。分析当日に調製した試 料を基準にその 2, 7，11 日間保存後の回収率の結果を Table 4 に示す.ノニルアルデヒドは保存期間とともに回 収率がやや低下するものの, 1 週間程度の保存が可能であ
つた。

\section{$3 \cdot 5$ 検量線の直線性}

VOC9 成分及び PAE2 成分の各 10〜 500 ng の範囲にお ける検量線の直線性を Table 5 に示す. VOC 及び PAE 各 成分の相関係数はそれぞれ $r=0.999$ 以上, $r=0.996$ 以上 （10 ng を除くと $r=0.999 ）$ と良好な直線性を示した. PAEの相関係数が低い原因は分析操作におけるコンタミ ネーションの影響により ${ }^{8)}$, 低濃度域で直線から外れてい るためであった。

\section{$3 \cdot 6$ 再現性}

VOC9 成分及び PAE2 成分の各 $100 \mathrm{ng}$ におけるピーク 面積の繰り返し再現性 $(n=5)$ を Table 5 に示す。相対 標準偏差はVOC で $1.5 \sim 2.0 \%$, PAE で 2.2〜 6.2\% と良 好であった。

\section{$3 \cdot 7$ 検出下限値}

VOC9 成分及びPAE2 成分各 $4 \mathrm{ng}$ の GC/MS の SCAN モードにおけるマスクロマトグラムのピーク高さより算出 


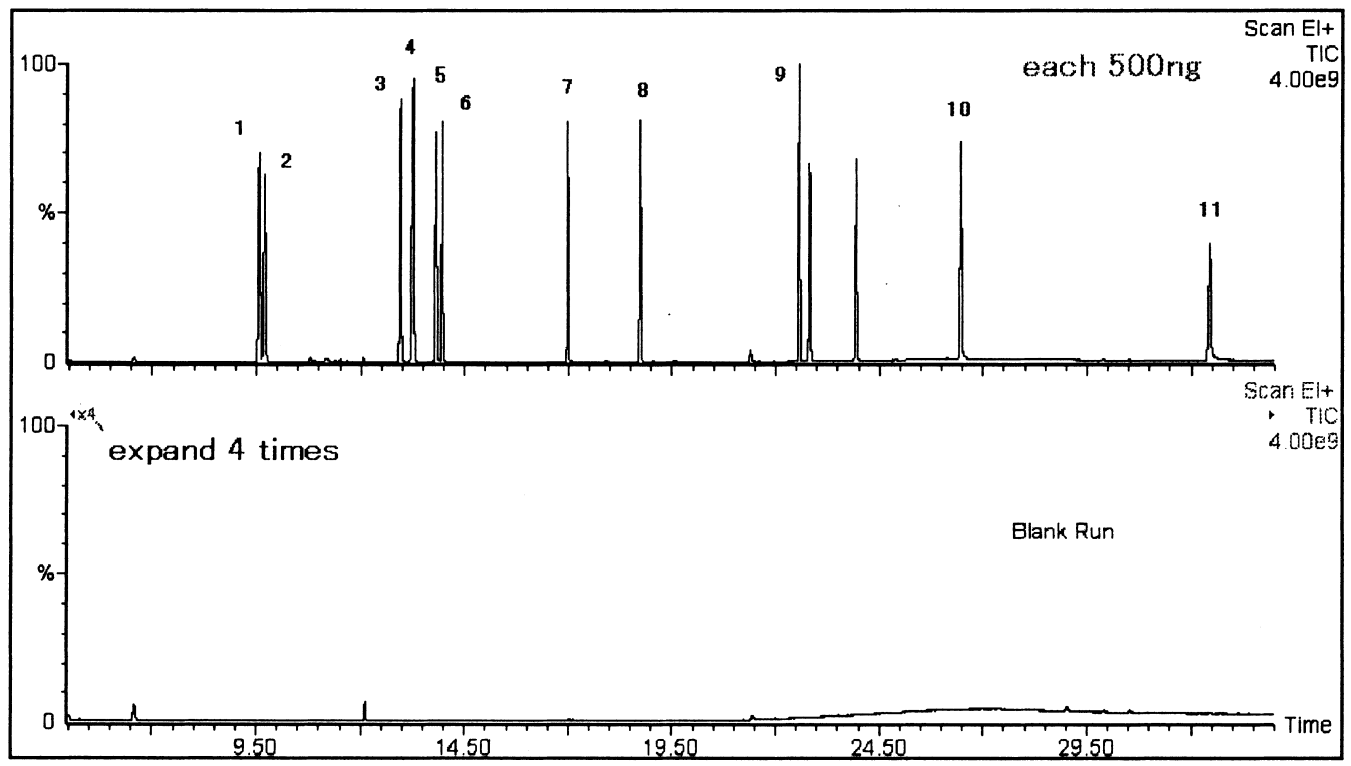

Fig. 2 Carryover for selected compounds

Blank run(lower chromatogram) shows the successive run performed with the same tube and analytical system, following the sample run (upper chromatogram). 1. Toluene- $d 8$, 2. Toluene, 3. Ethylbenzene, 4. $p+m$-Xylene, 5. Styrene, 6. o-Xylene, 7. $p$-Dichlorobenzene, 8. Nonylaldehyde, 9. Tetradecane, 10. DBP (dibutyl phthalate), 11. DEHP (diethyl hexyl phthalate)

Table 3 Carryover of tetradecane

\begin{tabular}{lc}
\hline \multicolumn{1}{c}{ Sorbent } & Carryover, $\%{ }^{\text {a) }}$ \\
\hline Air Toxics & 20 \\
TenaxTA/Carboxen1000 & 0.17 \\
TenaxTA & 0.15 \\
\hline
\end{tabular}

a) Blank run after $100 \mathrm{ng}$ analysis

Table 4 Storage and recovery of VOC and PAE

\begin{tabular}{lccrc}
\hline & 0 & 2 & \multicolumn{1}{c}{7} & 11 \\
\hline Toluene & 100 & 92.8 & 98.4 & 97.9 \\
Ethylbenzene & 100 & 95.0 & 101.1 & 97.0 \\
$p, m$-Xylene & 100 & 94.9 & 101.5 & 97.6 \\
Styrene & 100 & 95.2 & 100.6 & 97.4 \\
$o$-Xylene & 100 & 93.7 & 103.0 & 96.8 \\
$p$-Dichlorobenzene & 100 & 96.1 & 103.0 & 97.7 \\
Nonylaldehyde & 100 & 89.7 & 94.7 & 81.8 \\
Tetradecane & 100 & 96.3 & 101.5 & 97.6 \\
\hline
\end{tabular}

した， $S / N=10$ における検出下限值を Table 6 に示す。 厚生労働省が示すトルエン指針值が $260 \mu \mathrm{g} / \mathrm{m}^{3}$ であるの に対して，検出下限值 $0.07 \mathrm{ng}$ は試料採取量 31 のとき空 気中濃度 $0.02 \mu \mathrm{g} / \mathrm{m}^{3}$ に相当することから実分析に十分適 応できる。

\section{$3 \cdot 8$ 実分析}

実際に居住する住宅の室内空気の分析例を Fig. 3 に示 す。また，JIS 小型チャンバー法によるじゅうたんからの
Table 5 Correlation coefficient of calibration curve and repeatability

\begin{tabular}{lcc}
\hline Compound & Correlation coefficient, $R^{\mathrm{a})}$ & $\mathrm{RSD}, \%{ }^{\mathrm{b})}$ \\
\hline Toluene & 0.9999 & 1.9 \\
Ethylbenzene & 0.9998 & 1.1 \\
$p, m$-Xylene & 0.9998 & 1.0 \\
Styrene & 0.9997 & 0.9 \\
$o$-Xylene & 0.9998 & 1.0 \\
-Dichlorobenzene & 0.9996 & 1.2 \\
Nonylaldehyde & 0.9989 & 2.9 \\
Tetradecane & 0.9991 & 1.3 \\
DBP & 0.9979 & 3.5 \\
DEHP & 0.9971 & 8.1 \\
\hline
\end{tabular}

a) range: $10 \sim 500 \mathrm{ng}$; b) at $100 \mathrm{ng}(n=5)$

放散ガスの分析例を Fig. 4 に示す. 室内空気からは, 定 量の対象としたすべての成分を検出するとともに，リモネ ンなど室内に置かれた観賞用植物に由来すると考えられる 成分を検出した。じゅうたんからは，0.1〜 $200 \mu \mathrm{g} / \mathrm{m}^{3}$ を 定量した。また，定量の対象とした成分以外に，製造の工 程で使用したと推定される多くの溶剤成分を検出した。 TenaxTA では，破過容量の小さいアセトンなどの低沸点 成分の空気採取量に限界があり，AirToxics では高沸点成 分の回収が不完全である。TenaxTA/Carboxen1000では これらの問題を解決し，アセトンなどの低沸点成分から DEHP などの高沸点成分まで，一斉分析が可能であるこ とを確認した。 


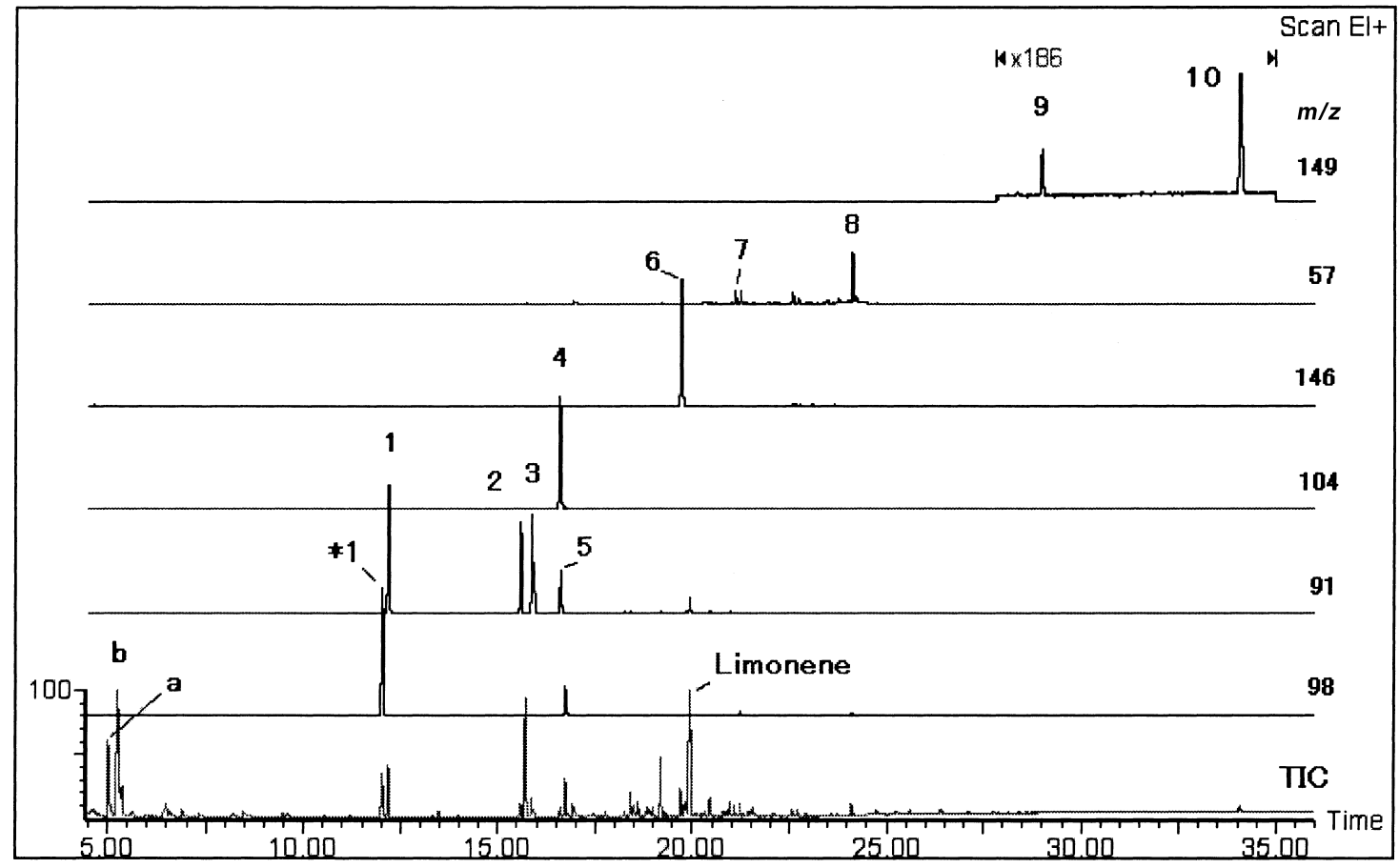

Fig. 3 Indoor air of a living room

The ions specified with $m / z$ in Table 6 are shown. *1. Toluene- $d 8$ (IS), 1. Toluene (34.4), 2. Ethylbenzene (7.3), 3. p,m-Xylene (15.9), 4. Styrene (1.1), 5. o-Xylene (4.5), 6. p-Dichlorobenzene (20.0), 7. Nonanal (8.8), 8. Tetradecane (2.7), 9. DBP [dibutyl phthalate] (0.46), 10. DEHP [diethyl hexyl phthalate] (5.6), a. Ethanol , b. Acetone

( ) : ng/l (sampling volume of $3.5 \mathrm{l}$ )

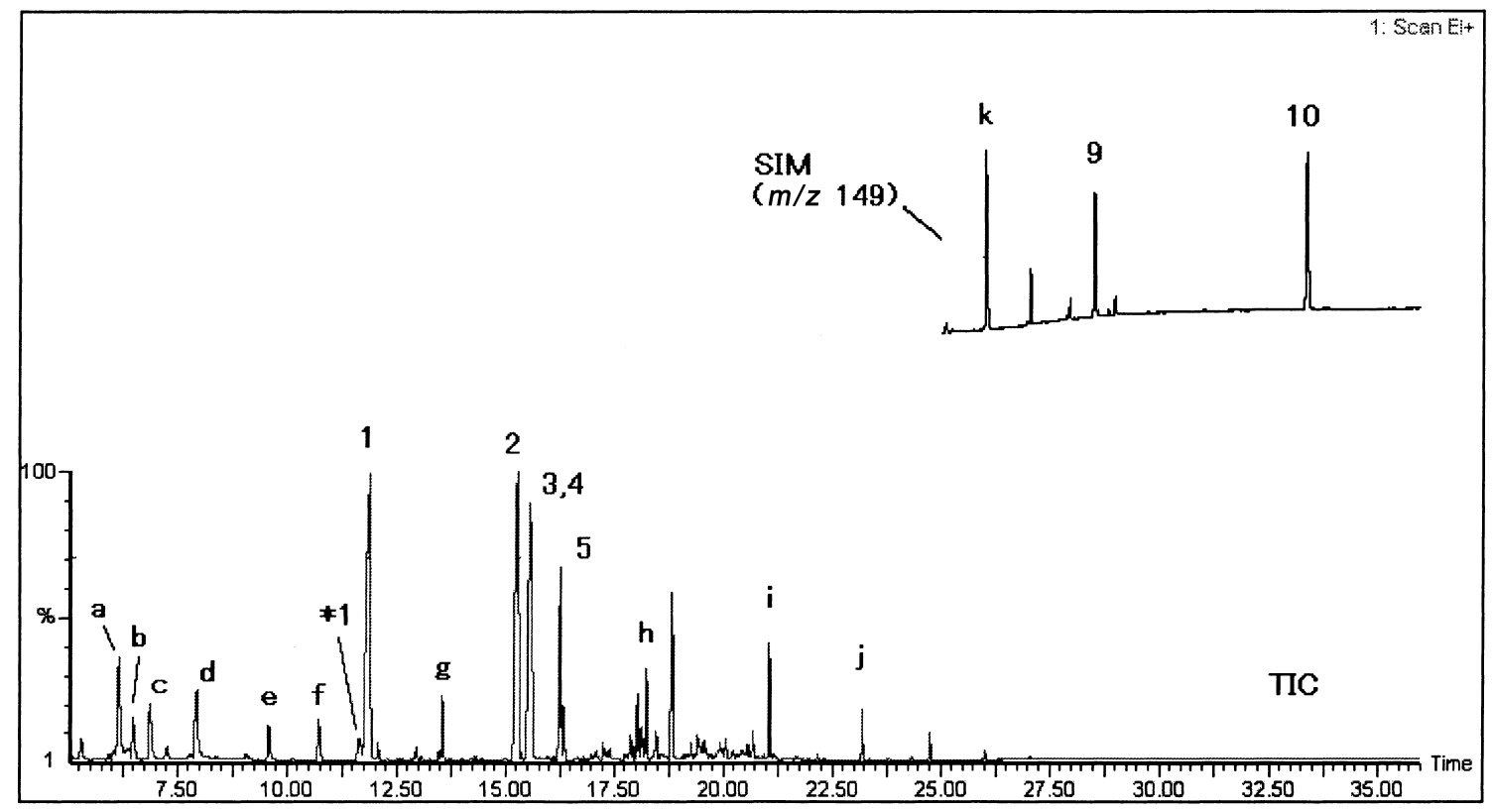

Fig. 4 Outgas emitted from a carpet

The specimen was placed in a 20-liter chamber standardized by JIS A1901 (2003). *1. Toluene- $d 8$ (IS), 1. Toluene (212), 2. Ethylbenzene (38), 3,4. p,m-Xylene (162), 5. o-Xylene (71), 9. DBP [dibutyl phthalate] (0.1) , 10. DEHP [diethyl hexyl phthalate] (1.00), a. Ethanol , b. Acetone, c. Methylacetate, d. $n$-Butanol, e. Methylmethacrylate, f. MIBK, g. Butylacetate, k. Siloxane-tetramer, i. Siloxane-pentamer, j. Siloxane-hexamer, h. DEP [dietyl phthalate], ( ): ng/l (sampling volume of 3.5 l) 
Table 6 Detection limit for GC/MS scan mode

\begin{tabular}{lcc}
\hline \multicolumn{1}{c}{ Compound } & $\begin{array}{c}\text { Quantitation ion } \\
(m / z)\end{array}$ & $\begin{array}{c}\text { Detection limits } \\
(\text { at } S / N=10)^{\text {a) }}\end{array}$ \\
\hline Toluene- $d 8$ & 98 & 0.23 \\
Toluene & 91 & 0.07 \\
Ethylbenzene & 91 & 0.10 \\
$p, m$-Xylene & 91 & 0.08 \\
Styrene & 104 & 0.22 \\
$o$-Xylene & 91 & 0.10 \\
$p$-Dichlorobenzene & 146 & 0.10 \\
Nonylaldehyde & 57 & 2.67 \\
Tetradecane & 57 & 0.12 \\
DBP & 149 & 0.42 \\
DEHP & 149 & 0.37 \\
\hline
\end{tabular}

a) unit: ng

\section{文献}

1) 厚生労働省: “室内污染空気污染に係るガイドライ ン”, (2000).

2) 厚生労働省：“室内濃度指針值およびそれらの測定 方法”, (2000).

3) JIS A 1901, 建築材料の揮発性有機化合物 (VOC), ホ ルムアルデヒド及び他のカルボニル化合物放散測定 方法一小型チャンバー法 (2003).

4) ISO/DIS 16000-6 "Indoor air -Part 6: Determination of volatile organic compounds in indoor, and chamber air by active sampling on TENAX TA sorbent, thermal desorption, and gas chromatography MSD/ FID”

5) 世古民雄, 臼倉浩一：第 7 回環境化学討論会講演要 旨集, p. 88 (1998).

6) T. Seko, N. Onda: Anal. Sci., 13, Suppl., 437 (1997).

7) 世古民雄，恩田宣彦：日本分析化学会第 49 年会講 演要旨集, p. 40 (2000).

8) 世古民雄, 臼倉浩一，恩田宣彦：第 7 回環境化学討 論会講演要旨集, p. 666 (2002). 